\title{
A Note on Prior Publication
}

Six of the essays by Dieter Henrich that are assembled here were originally published in German in the following places:

"Der Weg des spekulativen Idealismus. Ein Résumé und eine Aufgabe." In D. Henrich and C. Jamme, Jacob Zwillings Nachlaß. Eine Rekonstruktion (Hegel-Studien, suppl. 28), pp. 78-96. Bonn: Bouvier, 1986.

"Philosophisch-theologische Problemlagen im Tübinger Stift zur Studienzeit Hegels, Hölderlins und Schellings." Hölderlin-Jahrbuch 25 (1986-87), pp. 6o-92.

“Über Hölderlins philosophische Anfänge. Im Anschluß an die Publikation eines Blattes von Hölderlin in Niethammers Stammbuch." Hölderlin-Jahrbuch 24 (1984-85), pp. 1-28.

"Hölderlin über Urteil und Sein. Eine Studie zur Entstehungsgeschichte des Idealismus." Hölderlin-Jahrbuch 14 (1965-66), pp. 7396.

"Hegel und Hölderlin." In Dieter Henrich, Hegel im Kontext, pp. 9-40. Frankfurt am Main: Suhrkamp, 1971.

Der Gang des Andenkens. Beobachtungen und Gedanken zu Hölderlins Gedicht. Stuttgart: Klett-Cotta, 1986.

"Hölderlin in Jena" was written for this volume. 
